pulmonary and critical care medicine at the University of Michigan Medical Center. He has made extensive contributions to the osteopathic medical profession and serves as chairman of various committees, including the AOA Committee on Research Grants, the Physiology Test Construction Committee of the National Board of Examiners for Osteopathic Physicians and Surgeons, and the AOA Task Force on AIDS. He has been a member of the AOA Bureau of Research, where he actively participates in the AOA Research Conference. Dr. D'Alonzo is certified in internal medicine and in medical diseases of the chest by the American Osteopathic Board of Internal Medicine.

In addition, Dr. D'Alonzo has acted as manuscript reviewer for the JAOA, the American Review of Respiratory Diseases, Chest, Conceptual Therapeutics, and Chronobiology International. He is on the editorial board of Conceptual Therapeutics and M.D. Practice. He has published extensively in his specialty of exercise physiology, and was most recently named the outstanding clinician by the Department of Internal Medicine at the University of Texas Health Sciences Center at Houston.

Michael Patterson, Ph.D., also has a long history of accomplishment and contributions within the osteopathic medical profession. Dr. Patterson comes from an osteopathic medical family. He received his undergraduate degree from Grinnell College and his Ph.D. in psychology from the University of Iowa. Dr. Patterson served a postdoctoral fellowship in the neurophysiology of learning at the University of California.

Appointed to the faculty of the Kirksville College of Osteopathic Medicine in the Department of Physiology in 1971, he moved to the Ohio University College of Osteopathic Medicine six years later, where he now serves as director of research affairs and professor of osteopathic medicine. Like his colleague Dr. D'Alonzo, Dr. Patterson has published extensively, particularly on neurophysiologic alterations related to central and peripheral neurologic disorders. He is especially interested in the clinical syndrome of somatic dysfunction, assisting as a consultant and coinvestigator into the nature of this dysfunction.

Drs. D'Alonzo and Patterson will assist the Editor in Chief not only in the review of contributions but in seeking out the very best work performed within our institutions and by members of the osteopathic medical profession. Their assistance will help in our continued efforts. We welcome them to the editorial staff.

THOMAS WESLEY ALLEN, D.O., FACOI

\section{Examining future directions in osteopathic medical education and research}

The 1986-7 activities of the AOA and its Department of Education and Research may be characterized by two words-innovation and change. This issue of JAOA is designed to highlight certain major studies and projects that have grown from changes both internal and external to the osteopathic profession.

First, there is a series of three articles on osteopathic postdoctoral training. The internship and residency needs of the profession have been the subject of intensive assessment and action in the past few years.

Ralph Willard, D.O., was the chairman of a Task Force on Postdoctoral Training that was charged by the AOA Board of Trustees with projecting the needs of the profession over the next five to ten years. This article is a summary of specific parts of an extensive report presented to the Board of Trustees in July, 1987. The article focuses on the purposes of the Task Force, certain statistical projections, and the ultimate recommendations adopted by the board. The thrust is to move immediately toward mechanisms that will greatly expand osteopathic postdoctoral training opportunities throughout the United States.

The second article examines opinions gathered by the Task Force on Postdoctoral Training through interviews with policy and opinion leaders. Their responses reflect possible future directions. The five leaders were questioned by members of the Task Force using pre-designed questions but in an open-ended interview format. Because the interviews lasted an hour or more, the article is an abridged version of the actual surveys developed through my own editorial review of the complete interview text. I have attempted to provide a consistent format by limiting the article to individual responses to the same questions. Many extremely interesting and, at times controversial, opinions emerge as one reads these interviews.

The third article summarizes a report developed within the AOA Department of Education. The growth and development of the AOA-approved rotating internship has been the subject of massive activity within the profession over the past several years. This report illustrates the impact of colleges of osteopathic medicine on the growth of internships, both in terms of programs and approved positions. A clear trend exists toward more college involvement within the overall AOA internship program. This trend is expected to continue.

Of equal importance to the profession is the de- 
$\dot{\nabla}$ STUART PHARMACEUTICALS
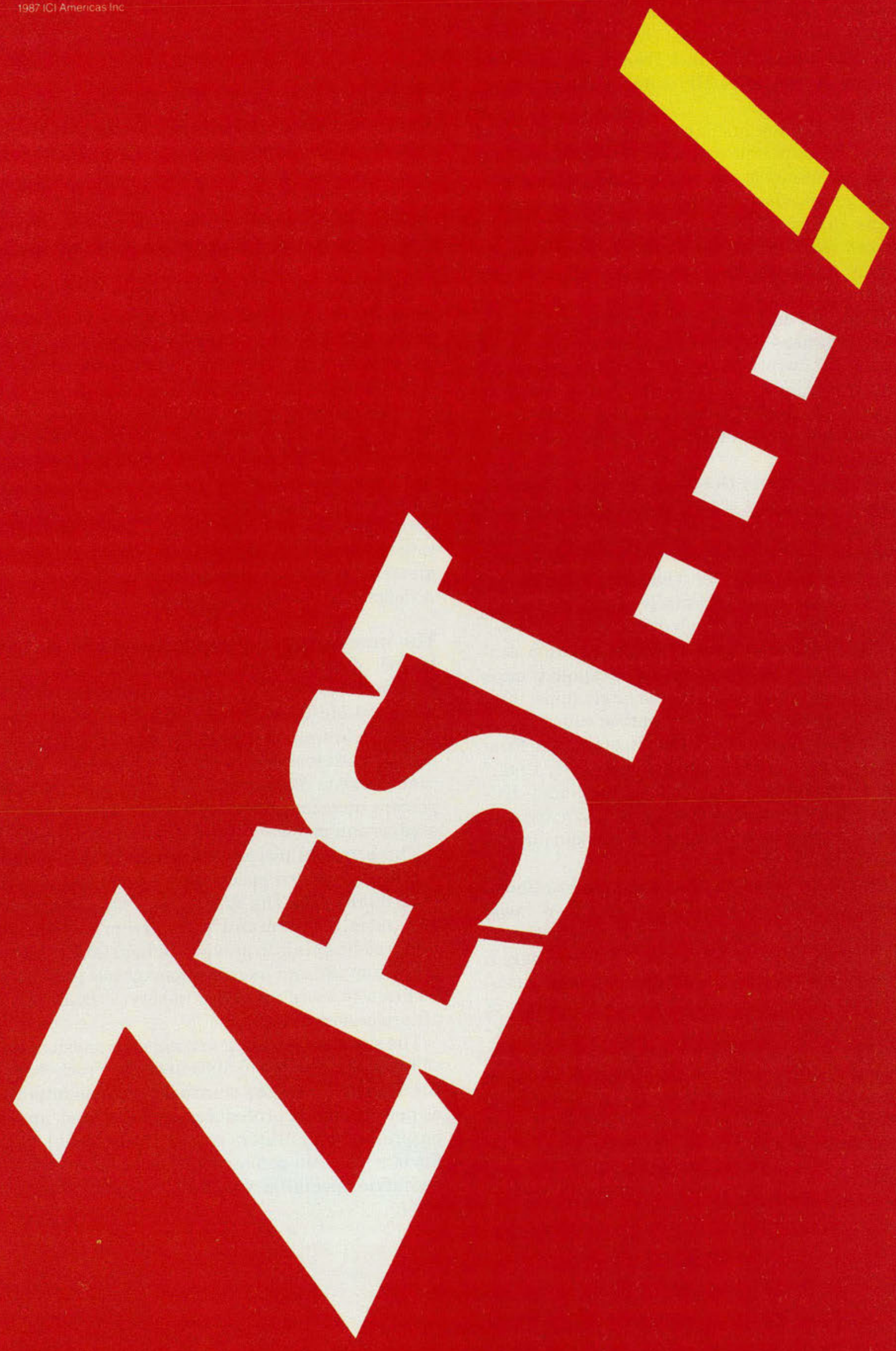
velopment of osteopathic hospitals. Article four is presented by William G. Anderson, D.O., and George A. Reuther. Dr. Anderson was the chairman of the AOA Task Force on Proprietary Multi-Hospital and other Multi-Hospital Systems. He was assisted in the work of this Task Force by Mr. Reuther, who directs the AOA Division of Hospital Accreditation.

The Task Force studied the current phenomena of hospital mergers and corporate realignment, suggested guidelines for osteopathic hospitals entering merger discussions, and presented recommendations to the AOA Board of Trustees. These practical recommendations are included here as one means of preserving osteopathic identity and interests.

Two articles emphasize an area of major change and importance-osteopathic research. David W. Rivers, Ph.D., wrote "AOA Initiatives in Research" in which he identifies major changes in the AOA Bureau of Research program, the goals to be achieved, and the development of D.O.s as clinical researchers.

An article by Gary Goldberg, director, Research Division, University of Medicine and Dentistry of New Jersey-School of Osteopathic Medicine, provides detailed insight into one college's research development program. Mr. Goldberg has stressed the vital importance of formally planning and institutionalizing the research effort.

As the elderly segment of the population continues to grow, meeting this demographic group's medical needs is becoming increasingly important. The final article, "Status of geriatric education in colleges of osteopathic medicine: Report of the First National Survey to Establish Benchmark Data," authored by Jerry Solon, Ph.D., and Nancy Kilpatrick, M.A., examines the amount of curricula devoted to gerontology and geriatrics during the 1983-4 academic year.

According to Webster's Dictionary, innovation is defined as "change made in established laws, customs, rites and practices by the introduction of something new." So what is new? To name only a few-altered health care environment, new education and training programs, changes in numbers of graduates, technological updates and breakthroughs.

Each of these articles is a response to changes that require innovations. Change is often difficult to accept, but nonetheless essential to each of us. I trust you will find this series valuable.

DOUGLAS WARD, PH.D.

Director, AOA Department of Education Chicago, Illinois

\section{editorial comment}

Vitamin $A$ is critical in the fight against measles in developing nations. Inexpensive doses of vitamin A are second only to immunization in preventing deaths among children with measles, according to a recent study by Alfred Sommer, M.D., M.H.S., professor of ophthalmology and international health at the Johns Hopkins Medical Institutions.

About 3 to 5 percent of children in developing countries die from measles complications, because few immunization programs exist and established ones fail to reach every child. In contrast, measles is a harmless childhood disease in the U.S.

This study provides the latest evidence of vitamin A's essential role in the body's defense system. UNICEF and the World Health Organization have jointly recommended that vitamin A supplementation be included in the treatment of all children with measles in countries where the death rate is 1 percent or greater, and in the treatment of all measles in cases in communities where vitamin A deficiency is a known problem.

The number of children hospitalized and the length of their hospital stays is decreasing. Unfortunately, however, a higher percentage of hospitalized children require intensive care these days. According to a recent survey, neonatal and pediatric intensive care patients increased 30 percent between 1980 and 1985 , compared to a 15 percent increase in adult intensive care patients in cardiac and medical units for the same period.

These trends place a premium on the nation's available pediatric specialists, especially the pediatric intensivist. The survey also found that younger patients, demanding more critical care, required hospitals to provide higher staffing ratios, greater space, and more equipment per patient, in addition to more intensive in-service training for all professional staff.

The supply of pediatric critical care physicians is tight, with only 200 to 300 currently practicing in the United States. As transport systems improve, as new lifesaving procedures are developed, and as hospital administrators realize the financial benefits of a well-run pediatric intensive care unit, the pediatric specialist will be increasingly sought after. 